\title{
La familia y la política según Aristóteles
}

Family and politics according to Aristotle

\author{
Johan Leuridan Huys \\ Universidad de San Martín de Porres, Perú
}

\section{Resumen}

Aristóteles señala la importancia de la familia para los asuntos políticos. Encontramos frases contradictorias que afirman la prioridad o la bondad de la familia o la bondad de la política. Los seres humanos se desarrollan en la polis, pero la familia tiene su autonomía propia para la educación en valores éticos a través del amor familiar y de pertenencia. La mayor ventaja es la amistad por medio de la cual se aprende en familia, y con los conflictos civiles disminuirán. Los líderes políticos necesitan la capacidad de gobernar y virtud moral. La relación entre un hombre y una mujer es agradable cuando ambos mantienen su dignidad.

Palabras clave: Aristóteles, la virtud ética y la virtud civil, por ejemplo, la familia, amistad, inteligencia, política.

\begin{abstract}
Aristotle points out the importance of the familiy for politics issues. We find contradictory phrases that assert the priority or the goodness of the family or the goodness of politics. Human beings develop in polis but the family has its own autonomy for education in ethical values trough family love and belonging. The greatest asset is friendship that is learned as a family, and with it, civil conflicts will decrease. Political leaders need the capacity of ruling and
\end{abstract}

Este es un artículo Open Access bajo la licencia Creative Commons Atribución-NoComercial-Compartirlgual 4.0 
moral virtue. The relationship between a man and the woman is pleasant when both maintain their dignity.

Keywords: Aristotle, ethical virtue and civil virtue, example, family, friendship, intelligent, politics.

\section{Introducción}

Jürgen Habermas, Susan Neiman, Luc Ferry y otros no están seguros de que la filosofía, tal como la conocemos, tenga futuro. El interés en las redes se centra principalmente en la economía. La filosofía se ha convertido en un análisis sobre áreas particulares bajo la influencia de la ciencia y de la tecnología, pero no puede reducirse a una disciplina universitaria o a una crítica infructuosa (un espíritu crítico solo puede eliminar los errores del pasado). La erudición y el escepticismo reemplazan el verdadero sentido de la filosofía: la reflexión sobre los grandes interrogantes como la felicidad, el sentido de la vida, la familia, mis relaciones con los demás, los ideales o la conciencia de las obligaciones. $Y$ es un callejón sin salida porque debería tratar de explicar la totalidad, contribuyendo al entendimiento de nosotros mismos y del mundo.

La filosofía posmoderna se siente feliz de haberse liberado de la opresión de los mandamientos, del sacrificio, de las costumbres, del principio de autoridad de los padres, del profesor y del dirigente político.

El liberalismo y el socialismo solamente soñaban en producir riquezas y armas. Se preocupaban por la relación del hombre con la materia, pero no de su relación con los demás. Producir, comprar, vender; sin mayor control sobre las ciencias y las tecnologías, con consecuencias nefastas para el futuro del planeta. Las ideologías y los gobiernos de todos los países del mundo solo han logrado un acuerdo común, pero para llenar el mar de plásticos.

La posmodernidad y la sociedad tecnócrata han cuestionado la ética. Los idealistas se han convertido en pragmáticos. Los resultados prácticos de la tecnología prescriben el orden político, el ético y el jurídico. En los planes de estudio de los colegios y universidades se han eliminado las asignaturas de humanidades y ciencias sociales. 
Baricco $^{1}$ señala las implicancias de la revolución digital. La PlayStation nos lleva a vivir en un mundo nuevo. La adhesión a la pantalla introdujo la norma del movimiento continuo. La realidad es cambio. Comprobamos el individualismo sin identidad: hombres que emiten juicios sin tener una opinión propia, dan órdenes sin poseer la competencia respectiva y deciden sobre su vida sin conocimiento suficiente acerca de esta.

La revolución digital transforma la cultura, el pensamiento y los comportamientos del hombre sin una adecuada maduración de las relaciones personales auténticas. Ya no se distingue entre la realidad y el mundo nuevo. Ya no se sabe la diferencia entre el bien y el mal. Vivimos en el ámbito del individualismo, limitado solamente por la exigencia de la tolerancia absoluta. Cada uno construye su propia vida sin ninguna referencia a los valores. En otras palabras, todas las relaciones humanas tienen el mismo valor. Ninguna forma de relación es mejor que otra. El gobierno no interviene, se mantiene neutral.

La persona que critica la falta de ética de otros es calificada como antidemocrática. La justicia, considerada como fundamento de la política desde la antigüedad, es hoy en día reemplazada por la norma de la democracia. Sin embargo, las instituciones de libertad (sistema democrático de las elecciones, los tres poderes del Estado y la economía de mercado) son estructuras funcionales de vidrio y hormigón a las que nos hemos acostumbrado, pero en las que no es fácil encontrar un sitio familiar y acogedor. No ofrecen un sentimiento de pertenencia moral. Faltan ligaduras más profunda. ${ }^{2}$

La familia es la víctima principal de esta situación porque su crisis afecta la parte más importante del ser humano: la educación en valores que se recibe principalmente en el seno del hogar. «Uno de los ámbitos en los que las ideas sobre la inacción estatal y la 'libertad' negativa han resultado particularmente perniciosas ha sido el de la relación con el Estado, con el hogar o la familia». ${ }^{3}$

\footnotetext{
Alessandro Baricco, The Game (Barcelona: Editorial Anagrama, 2019), 95 y 220.

Ralf Dahrendorf, El recomienzo de la historia (Buenos Aires: Katz Editores, 2006), 80.

Martha Nussbaum, Crear capacidades (Barcelona: Espasa Libros S. L. U., 2017), 98.
} 
Muchos adultos (los padres de familia y los políticos) han perdido el control sobre la juventud porque no le ofrecen ideales y tampoco pueden ser ejemplos. Hay padres que quieren encargar la educación a los profesores. Sin embargo, la escuela no puede reemplazar a la familia donde esta fracasa. El docente no ve al niño en todas las dimensiones de su personalidad, sino solo como alumno. Los docentes enseñan y la familia educa. El niño, el púber y el joven necesitan madurar en un ambiente de afecto y pertenencia.

Esta situación origina también el bullying y la falta de respeto hacia el profesor en las escuelas y colegios. Para resolver la actitud de un niño que agrede físicamente a su maestro hay que llamar a la policía. Los padres le darán siempre la razón al hijo porque han perdido toda autoridad y solo les queda engreír. Hay países donde ellos deciden si sus hijos aprueban o desaprueban el año académico.

La teoría del género, en su interpretación extrema, pretende que los gobiernos intervengan en la familia, pero para quitarle la educación de los hijos. Se declaró la familia democrática. Los hijos son autónomos. Van a construir su propia vida con los criterios que reciben del profesor y evidentemente también bajo la influencia del entorno social, donde dominan muchos malos ejemplos de dirigentes políticos; el estilo de vida de drogas, alcohol, sexo y violencia de los cantantes y de los astros de Hollywood; y la postura de los líderes de la tecnología que han impuesto la ley exclusiva de la competitividad de producción y consumo, eliminando todo otro sentido o finalidad. Se han perdido los valores de la intimidad, el afecto y la pertenencia que solo pueden ser dados por la familia. El resultado es el déficit, ya en algunos países, para encontrar docentes porque ya no se puede enseñar a niños indisciplinados.

De acuerdo con la Organización Mundial de la Salud hay países, considerados paraísos de desarrollo, entre los treinta con más suicidios infantiles o de menores de edad a nivel mundial, como Finlandia, Corea del Sur, Japón, Suiza, Francia, Bélgica, Rusia, Austria, Suecia y Dinamarca.

A pesar de las grandes preocupaciones por la igualdad de varones y mujeres en la familia y en la sociedad, el feminicidio no cesa. Hay países importantes en Europa donde la cantidad de mujeres asesinadas sobrepasa 
el centenar por año y donde las mujeres no se atreven a presentar sus quejas en las comisarías porque las atienden con burlas. En Suecia la violencia en las familias triplica la de España.

En el Poder Judicial se considera que los violadores y asesinos no son culpables porque no tuvieron una buena educación. Los jueces los envían a un instituto de rehabilitación por un año. Salen libres y vuelven a delinquir. ¿El ciudadano no tiene derecho a seguridad? Como consecuencia, se producen miles de vacantes en la policía porque los jueces malinterpretan sus intervenciones.

En este contexto, el presente artículo es el resultado de una indagación sobre uno de los más grandes pensadores de la historia que, cientos de años antes de Cristo, señaló la importancia de la familia para la política.

\section{La familia, la pertenencia y el amor familiar}

Para Aristóteles cada ciudad es una comunidad constituida con miras al bien común. Existen dos instituciones naturales: la ciudad y la familia. Para que la primera se convierta en comunidad se necesita un conjunto de familias, en orden a una vida perfecta y autosuficiente. Por eso surgieron en las ciudades relaciones familiares, fratrías, fiestas y diversiones para vivir en común, decisión que es fruto de la amistad. ${ }^{4}$

En una primera instancia, Aristóteles afirma la prioridad de la familia sobre el Estado:

La amistad del varón y la mujer, por otra parte, parece existir estrictamente por naturaleza; pues el hombre por naturaleza tiende más a vivir acompañado en pareja que a ser ciudadano, porque antecede y es más necesario el hogar que las ciudades (...) De este modo, los demás forman comunidades por necesidad, pero el hombre y la mujer conviven no solo para la reproducción, sino también por todo lo que implica la vida. Conforme a esto

\footnotetext{
4 Aristóteles, Política, trad. Carlos García Gual y Aurelio Pérez Jiménez (Madrid: Alianza Editorial, 2018), III, 9 .
} 
enderezan y distribuyen sus actividades respectivas el varón y la mujer complementándose recíprocamente, tanto en lo común como en lo individual; y así, también aquí, de lo conveniente y agradable, resulta otro particular modo de amistad. Y si ambos son dignos y ecuánimes, su relación resulta virtuosa y además agradable. Los hijos, a su vez son el lazo de unión; y por eso, parece que se divorcian los que no tienen hijos, pues los hijos son un bien mutuo para ambos, que los mantiene en lo común. ${ }^{5}$

No se puede vivir de cualquier manera. Surge la pregunta decisiva: ¿qué son la dignidad y la relación virtuosa?

El libro Ética a Nicómaco fue el inicio de la reflexión sobre la ética en la antigüedad griega: ¿cómo uno se vuelve virtuoso? A partir de esta pregunta de Aristóteles empieza la reflexión ética. ${ }^{6}$ En contra de Platón y de Sócrates, Aristóteles insiste en que el comportamiento humano no es automático. Este es el punto de partida de la ética. La filosofía es para Aristóteles una tarea profundamente ética. Es conocida su frase: «Como el hombre perfecto es el mejor de los animales, apartado de la ley y de la justicia, es el peor de todos».

Aristóteles es el gran representante de la filosofía que ubica al bien moral como la noción central de la ética. Para él la moralidad coincide con la felicidad. «Es lo mismo vivir bien y obrar bien que ser feliz». El hombre desea su realización: el bien. El bien es el concepto central y fundamental que cada hombre debe tener si quiere ser hombre. Sin embargo, a diferencia de Platón, para Aristóteles el bien no está en una idea perfecta. Hay un bien de Dios, otro de los hombres, otro de los animales y otro de los minerales. A cada uno de estos seres le corresponden sus bienes particulares. El hombre va forjando su propio bien. La diversidad de los bienes morales o virtudes no significa una diversidad de fuentes de origen. ¿Cómo se fundamenta el bien moral del hombre?

Aristóteles, Ética a Nicómaco, trad. Salvador Rus Rufino y Joaquín E. Meabe (Madrid: Editorial Tecnos, 2009), VIII, 12.

6 Gwenwaëlle Aubry, «Dunamis et Energeia dans l'Éthique Aristolicienne: l'Éthique du Demonique», en L'excellence de la vie, dir. Gilbert Romeyer Dherbey y ed. Gwenwaëlle Aubry (Paris: J. Vrin, 2002), 8182. 
Para Mario Vegetti la naturaleza significa la norma de los procesos, el principio de valor que permite ordenar una escala jerárquica. La naturaleza del hombre es excepcional porque Aristóteles lo considera el animal más acorde con la naturaleza porque su naturaleza no está predeterminada como la de los animales. Para él los otros animales son anomalías de la norma natural (PA, II, 10, 656 a 7-12, IV, 10,686 b 2-5). El concepto de naturaleza pasa de una definición biológica y estadística a una definición axiológica. La naturaleza como norma y valor, idea ya presente en sus obras de física y biología, se vuelve en su antropología un fundamento prescriptivo en lugar de uno meramente descriptivo. Vegetti considera que las formas de la ciudad aparecen normativas en relación con la esencia de la naturaleza humana. La definición del hombre como un animal político es la afirmación de que este solo se realiza en la ciudad, donde están unidas la ética y política. Si bien el hombre tiene una situación histórica, el fundamento antropológico permite entenderlo a él y a la sociedad en general, tan atemporales y perpetuos como la naturaleza. ${ }^{7}$

¿En qué consisten el conocimiento y la ejecución de los valores?

El hombre posee un conocimiento sensitivo e intelectual. El contacto con la realidad es por medio de los sentidos, que brindan un conocimiento fugaz y circunstancial.

El intelecto, en primer lugar, proporciona el conocimiento de las causas y el sentido del entorno mediante los conceptos abstractos y universales que permiten la comunicación y entendimiento con los demás a través del logos. En segundo lugar, el intelecto tiene también la capacidad deliberativa para decidir entre el bien y el mal. Se trata de una moral de intención y brota del interior de la persona. «El principio está en nosotros». ${ }^{8}$ La naturaleza no impone la virtud. La virtud es la libre elección del bien por la razón.

Mario Vegetti, «Normal, natural, normatif dans l'Éthique d'Aristote», en L'excellence de la vie, dir. Gilbert Romeyer Dherbey y ed. Gwenwaëlle Aubry (Paris: J. Vrin, 2002), 68-69.

8 Aristóteles, Ética a Nicómaco, III, 3. 
Aristóteles define las virtudes de la siguiente manera:

Las éticas se generan en las costumbres (...) toda virtud, cualquiera que sea, se forma y se destruye absolutamente por los mismos medios y por las mismas causas que uno se forma y se desmerece en las artes. Tocando la cítara, hemos dicho, se forman los buenos y los malos artistas; (...) si el arquitecto construye bien, es un buen arquitecto; es malo si construye mal. Lo mismo absolutamente sucede respecto a las virtudes. A causa de nuestra conducta en las transacciones de todos géneros que intervienen entre los hombres, aparecemos unos justos y otros inicuos. A causa de nuestra conducta en las circunstancias peligrosas, y después que contraemos en ellas hábitos de flojedad o de firmeza, nos hacemos unos valientes, otros cobardes. Lo mismo sucede con los resultados de nuestras pasiones (...) los unos son moderados y dulces, los otros intemperantes y dados a excesos. ${ }^{9}$

Las principales virtudes en la filosofía de Aristóteles son la justicia, la fortaleza y la templanza. Menciona aquí también el amor entre la pareja y el amor entre ambos y por sus hijos. No encontramos en su filosofía una teoría del amor, pero sí una extensa reflexión sobre la amistad, cuya definición se acerca mucho al amor cristiano. ${ }^{10}$ La felicidad no puede depender de un placer momentáneo o de una obsesión de satisfacción, su característica es una satisfacción respecto de la vida en su conjunto. Por tanto, las insatisfacciones controladas nos pueden llevar a la depresión y angustia. Para ser un hombre feliz no es suficiente un acto bueno, sino el hábito, la costumbre o la actitud de actuar siempre bien. La virtud es una adquisición.

Para poder aplicar los valores se necesita la prudencia o conocimiento práctico, la virtud intelectual. No es una reflexión sino una deliberación. Se trata de aprender a evaluar todos los elementos en las situaciones complejas de la vida y tomar la decisión adecuada en relación con los valores. Para adquirir el bien moral, la verdadera virtud, se requiere la elección del bien por la razón y su aplicación por la virtud intelectual: la prudencia (llamado la praxis).

\footnotetext{
Aristóteles, Ética nicomaquea, trad. Patricio de Azcárate (Buenos Aires: Editorial Losada, 2004), II, 1.

10 Ivan Gobry, La philosophie pratique d'Aristote (Lyon: Presses Universitaires, 1995), 88.
} 
La elección de una manera de vivir es teórica, pero al mismo tiempo es práctica porque para vivir bien necesito saber cuál es la mejor vida. La persona aprende a fijar el sentido de su vida y a tomar decisiones sobre situaciones prácticas a partir de los valores. La decisión es tomada por la prudencia, pero está fundada en las virtudes morales.

La inteligencia, las virtudes morales y la prudencia necesitan también la colaboración de las pasiones. Ellas son indispensables porque son inherentes al ser humano y tienen una presencia activa y positiva cuando están acompañadas por la razón (a diferencia de Platón que las ve exclusivamente como origen del mal). Las pasiones son las fuertes motivaciones para poder cumplir con el bien.

Platón quiso eliminar los vínculos familiares. Aristóteles le contesta:

Consideramos, pues, que la amistad es el mayor de los bienes en las ciudades, ya que con ella se reducirán al mínimo los enfrentamientos civiles. Pero en la ciudad forzosamente resultará aguada la amistad o comunidad semejante en la que llame sólo de modo tan mínimo 'mío' el hijo al padre y el padre al hijo. Así como un poco de dulce mezclado con mucha agua resulta imperceptible en la mezcla, así ocurrirá con el parentesco mutuo al que se refieren estos nombres, y en un régimen semejante estarán mínimamente obligados a cuidarse el padre de sus hijos o el hijo de su padre y los hermanos entre sí. Pues hay dos motivos, fundamentalmente, para que los hombres se tengan mutuo interés y afecto: la pertenencia y el amor familiar. Y ninguna de estas cosas puede subsistir bajo tal forma de gobierno. ${ }^{11}$

Aristóteles entiende a la familia como una amistad, como el mayor de los bienes. Sin embargo, afirma que esta es diferente de las amistades de conveniencia que existen en otros ambientes. La amistad en familia siempre se refiere a la relación con los padres. Los padres aman a sus hijos como si fueran parte de ellos y los hijos a sus padres por proceder de estos. El vínculo es estrecho para quien ha engendrado porque lo que nace de uno se considera un resultado propio.

11 Aristóteles, Política, II, 4. 
Los hijos quieren a sus progenitores por haber nacido de ellos y los hermanos se quieren por su propio nacimiento, y por todo lo que implica participar de la reciprocidad que de ello resulta y, por eso, se habla de la misma sangre, las raíces, y otras peculiaridades. Son, en cierto modo, lo mismo, pero separadamente (...) De ahí, entonces, que la amistad de los hijos hacía los padres, y la de los hombres hacia los dioses se muestra apropiada y del más alto rango. ${ }^{12}$

La amistad empieza en la familia y se extiende a la vida política. La familia es la condición previa y necesaria para lograr una buena sociedad. La amistad cultivada en el seno del hogar conseguirá también «reducir al mínimo los enfrentamientos civiles», como leímos en la respuesta de Aristóteles a Platón. Una persona que ha aprendido a amar y ha tenido la experiencia de ser amado sabrá brindar un trato adecuado en la política.

La marginalización de la familia en la educación generará una sociedad conflictiva porque al ser humano le faltará la educación de pertenencia a otros que lo quieren. Estará inseguro y fácilmente pasará a violencia verbal o física. Los hijos reconocen el amor de sus padres hacia ellos y aprenden a amarlos. Es un proceso que abarca la niñez y la juventud. Posteriormente se extiende hacia todos en la nación. La política necesita este apoyo emocional de personas que aprendieron el amor y los valores o virtudes.

La ética de las virtudes es el mejor método de educación y el ejemplo es el método preferencial para adquirir la ética. Ver personas que muestran dignidad por su respeto a los valores y por sus logros y sacrificios generan en los demás el deseo de imitarlos y de esa manera respetarse a sí mismos.

Y del mismo modo que las leyes imponen los deberes en la ciudad, en la casa prevalece la autoridad del padre, sus palabras y costumbres, tanto por el parentesco como por los servicios que aporta la familia, pues los hijos están, además, predispuestos al amor y a la obediencia al padre por naturaleza. Por otra parte, la educación particular es superior a la pública. ${ }^{13}$

\footnotetext{
12 Aristóteles, Ética a Nicómaco, VIII, 12.

13 Ibid., X, 9.
} 
Se puede imponer valores, pero a menudo no tienen aceptación. Uno puede recomendarlos, pero quedan en palabras. No existe la voluntad de cumplirlos. La ética kantiana no considera el aspecto de educación porque el deber se cumple o no se cumple. La ética de las virtudes no solamente indica cómo debe uno vivir, sino que ayuda a aprender a vivir, mediante la formación y el ejercicio activo. Se reflexiona sobre el bien de cada uno y cómo adquirirlo. El requisito está en desarrollar las buenas costumbres en la persona.

«No es, pues, de poca importancia contraer desde la infancia y lo más pronto posible tales o cuales hábitos; por el contrario, es éste un punto de muchísimo interés, o por mejor decir, es el todo». ${ }^{14}$ Esta frase indica que la educación en la familia del niño y del joven es decisiva para el resto de la vida.

\section{La política, la virtud cívica y la virtud ética}

Después de haber reconocido la primacía de la familia, Aristóteles afirma lo contrario:

Es decir que, por naturaleza, la ciudad es anterior a la casa y a cada uno de nosotros. Ya que el conjunto es necesariamente anterior a la parte. Pues si se destruye el conjunto ya no habrá ni pie ni mano, a no ser con nombre equívoco, como se puede llamar piedra una mano. Eso será como una mano sin vida. Todas las cosas se definen por su actividad y su capacidad funcional, de modo que cuando éstas dejen de existir no se puede decir que sean las mismas cosas, sino homónimas. Así está claro que la ciudad es por naturaleza y es anterior a cada uno. ${ }^{15}$

El político es un gobierno de hombres libres e iguales. La igualdad consiste en lo idéntico para los semejantes. El hombre tiene el deseo «por naturaleza» de formar una comunidad en la cual se cumpla su autosuficiencia y el vivir bien. Todas las comunidades pretenden el bien, pero sobre todo el bien superior, el bien común, que comprende a todos.

14 Aristóteles, Ética nicomaquea, II, 1.

15 Aristóteles, Política, I, 2. 
Por tanto, también es posible responder a la cuestión que algunos investigan y proponen: algunos, en efecto, se preguntan si el legislador, que quiere establecer las leyes más rectas, ha de legislar mirando a la conveniencia de los mejores, o a la mayoría, cuando sucede lo dicho. Lo recto hay que entenderlo en términos de igualdad; y lo recto en términos de igualdad se refiere a lo conveniente para toda la ciudad y para el común de los ciudadanos». ${ }^{16}$

Aristóteles critica el ostracismo que está presente en todas las formas de gobierno: tiranías, monarquías y democracias. Todas eliminan y deportan a los mejores. Sin embargo, considera que el gobierno de los libres es más noble y más conforme a la virtud que el gobierno del despótico.

«El ciudadano sin más por ningún otro rasgo se define mejor que por su participación en la justicia y en el gobierno». ${ }^{17} \mathrm{Su}$ virtud está necesariamente referida al régimen político: la virtud cívica.

Quienes destacan en las virtudes civiles deben ser elegidos para gobernar. Los candidatos para los cargos políticos deben cumplir, en primer lugar, con los requisitos de capacidad política o la virtud política. Hay que saber el bien del orden socio-político-económico y saber aplicarlo por medio del conocimiento práctico. Hay que saber hacer el bien. Se puede poseer la virtud ética, pero no la virtud cívica que es la aptitud para gobernar.

Aristóteles relaciona la política principalmente con la virtud de la justicia. Cuando en la actual sociedad se discute sobre la justicia distributiva, nos referimos a los ingresos, a la riqueza y a sus posibilidades. También la considera primordial, pero no solamente como distribución del dinero y de participación. Más importante es a quiénes se va a elegir, quiénes tienen el derecho para darnos órdenes y distribuir correctamente los bienes. Los líderes de las sociedades son responsables de las instituciones. Las personas deben poder encontrar la justicia en ellas. Los problemas no se resuelven cambiando los irresponsables por otros irresponsables, sino por líderes con una conciencia de la responsabilidad moral.

\footnotetext{
16 Ibid., III, 13.
}

17 Ibid., III, 1. 
El fin de la ciudad no es la mera convivencia. ¿Cuál es el fin de la política?

Es evidente que ha de preocuparse por la virtud la que de verdad se llama ciudad y no solo de palabra. Pues, en otro caso, la comunidad se convierte en una alianza militar que solo se diferencia espacialmente de aquellas alianzas con pueblos distintos, y la ley en un pacto que, como decía el sofista Licofrón, es garante de los derechos mutuos, pero incapaz de hacer buenos ciudadanos (...) Si uno fuera carpintero, otro campesino, otro zapatero y otro algún oficio similar, fueron unos diez mil en número, pero no se comunican para nada más que asuntos como el comercio y la alianza militar, tampoco en ese caso hay una ciudad (...) Fin de ciudad es, por tanto, el bien vivir, y todo eso está orientado a ese fin. La ciudad es la asociación de familias y aldeas para una vida perfecta y autosuficiente. Y ésta es, como decimos, la vida feliz y bella. Pues la decisión de vivir en común es amistad. Hay que suponer, en consecuencia, que la comunidad política tiene por objeto las buenas acciones y no sólo la vida en común. ${ }^{18}$

Está claro, pues, que es posible, siendo buen ciudadano, no poseer la virtud según la cual se es hombre bueno. El hombre puede utilizar en sentidos muy opuestos sus capacidades, tanto para robar y matar a otros como para un buen gobierno y un orden justo en la ciudad. Es necesaria una opción entre un tipo de vida u otro. Virtudes políticas y virtudes éticas son virtudes diferentes. Sin embargo, todos los ciudadanos han de participar de las virtudes morales y el que manda debe poseer perfecta la virtud ética (ya que su función propia es la de jefe de la acción, y el director de la acción es la razón). ${ }^{19}$

La justicia es el orden de la sociedad cívica, y la virtud de la justicia consiste en la apreciación de lo justo. La felicidad acompaña necesariamente a la virtud. El ideal para una vida feliz es, para Aristóteles, una vida en comunidad y un ideal compartido por todos. El bien político es la justicia. La formación más alta de justicia es una forma amistosa. Donde hay amistad no hace falta

\footnotetext{
18 Ibid., III, 9.

19 Ibid., I, 3.
} 
la justicia. En referencia a la respuesta de Aristóteles a Platón, en la que manifiesta que el mayor de los bienes, la amistad, se aprende en familia y este aprendizaje es imprescindible para evitar los enfrentamientos civiles en el Estado.

Se pueden prevenir muchos conflictos en la ciudad cuando el individuo ha recibido la educación en las virtudes; es decir, la dignidad. Las personas que no la recibieron son inseguras y proclives a la violencia verbal o física. Aristóteles relaciona la política con la ética. Reconoce que ciudad y familia son naturales y tienen su propio aporte. La justicia democrática nos permite vivir como personas libres, competentes en las cosas buenas y justas. La política debe promover a los hombres a que se vuelvan nobles. Todos deben participar en la vida política. Concierne a la política hacer a sus ciudadanos competentes, con sabiduría práctica y participación en el gobierno.

Los políticos hacen las leyes. Los que hacen las leyes tornan buenos a los miembros de la ciudad porque se adquiere los hábitos por las leyes. La ley tiene fuerza obligatoria y es el resultado de una experiencia e inteligencia. La ley no es odiada cuando ordena obrar bien porque las leyes de la política permiten a los ciudadanos ejercer la libertad. Los resultados dependen de las buenas leyes.

Hay una relación mutua entre las leyes y los hábitos. Los hábitos necesitan las leyes para poder adquirir las costumbres, pero las leyes a su vez necesitan los hábitos para ser cumplidas.

¿Cómo se puede persuadir a que el hombre mejore? Las pasiones, en general, no siempre ceden ante la razón, sino ante la fuerza. Son inherentes a los seres humanos para las virtudes o para los vicios. A la mayoría -y sobre todo a los jóvenes- le disgusta la vida austera y dura. Y quizá no resulte suficiente haber recibido una recta educación en la juventud. El carácter debe ser forjado con alguna disciplina porque se obedece más a la necesidad que a la razón, a los castigos más que a las recomendaciones. ${ }^{20}$

20 Aristóteles, Ética a Nicómaco, X, 9. 
La educación y las costumbres de los jóvenes deben ser instituidas por las leyes. Se debe desterrar entre ellos el lenguaje obsceno y los relatos o representaciones inconvenientes. Las leyes deben enfocar una práctica de cara a la edad adulta y para toda la vida. Los magistrados también consideran que se debe imponer sanciones y correcciones a los desobedientes de manera gradual. El bueno escuchará razones, mientras que el cuerpo dominará al alma en el caso del comportamiento vicioso e inclinado a los bajos placeres. Él solo entiende el castigo con dolor.

La educación en la sociedad política consta de cuatro disciplinas: lectura y escritura, gimnasia, música y dibujo, referido este a la vida técnica, comercial y a la belleza de los cuerpos.

Durante sus cinco primeros años los niños reciben la educación exclusivamente en casa. Pasada esta edad deben asistir a la escuela para aprender enseñanzas comunes hasta los veintiún años.

El genio de Aristóteles resulta también ser un buen padre de familia que se preocupa por sus hijos. Él da una serie de indicaciones concretas sobre esta etapa, por ejemplo: «Respecto a las rabietas de los niños y sus llantos, no aconsejamos acertadamente los que las prohíben en las leyes; pues son convenientes para el desarrollo, ya que vienen a ser en cierto modo un ejercicio para el cuerpo». ${ }^{21}$

Aristóteles le concede suma importancia a la música, tanto si es sola o con acompañamiento de canto. Él cita al poeta Museo, quien afirma que «el cantar es lo más dulce de los mortales». La música no solo produce placer, sino también contribuye a la formación del carácter y del alma. Produce entusiasmo en los espíritus, y el entusiasmo es una afección del carácter del alma.

Y en los ritmos y las melodías se dan muy especialmente imitaciones conforme a su propio natural de ira y de mansedumbre, y también del valor y la templanza, así como de sus contrarios y de las demás disposiciones morales (...) La música procura cierta calidad de ánimo y se debe educar en ella a los

21 Aristóteles, Política, VIII, 5. 
jóvenes. A los jóvenes les gusta el placer y la música es, por naturaleza, una de las cosas placenteras. ${ }^{22}$

Todas las formas, para lograr la virtud, autoridades, leyes, padres de familia, profesores, suponen siempre un grado menor o mayor de violencia. Sin embargo, la obligación impuesta no elimina la libertad, como lo manifiesta Jean-Baptiste Gourinat cuando afirma que Aristóteles no deja de repetir que la moral y la virtud consisten en la capacidad de elegir el bien. Aristóteles aclara que cada uno es siempre causante de sus actos desde el inicio hasta el final. ${ }^{23}$

Para concluir estas reflexiones volvamos a la pregunta de Aristóteles sobre qué tipo de vida es el más deseable. Hay tres clases de bienes: los externos, los del cuerpo y los del alma. Existe una discusión sobre la cantidad excepto para la riqueza, el dinero, la gloria y el poder que no deberían tener límites. Aristóteles considera fácil refutar este pensamiento. Los bienes externos tienen un límite y su exceso perjudica o no sirve para nada a quienes los tienen. Debemos admitir que hay una relación de superioridad entre las cosas. El alma es más valiosa que el cuerpo y la fortuna. Gracias a ella los bienes son deseables por todas las personas sensatas, pero no gracias a los bienes externos al alma.

Cada uno de los bienes relativos al alma, cuanto más abundante tanto más útil es, si debemos atribuirles no solo la belleza, sino también la utilidad (...) Una ciudad no estará feliz cuando no existe obra buena de varón ni de ciudad sin intervención de la virtud y la inteligencia. ${ }^{24}$

Las cualidades morales permiten la ejecución óptima de la práctica moral. Cuando hablamos de una «buena persona» o de un «hombre confiable» nos referimos a alguien que siempre buscará el bien en cualquier circunstancia. Uno no puede vivir con otro sin conocer la confianza moral de este. Un ser humano sin valores es una persona fingida. La praxis de la prudencia no solamente se refiere a las acciones por realizar, sino también a cómo uno hace las cosas, cómo las siente y cómo reacciona ante ellas.

22 Ibid., VIII, 5.

23 Jean-Baptiste Gourinat, «Délibération et choix dans l'éthique aristotélicienne», en L'excellence de la vie, dir. Gilbert Romeyer Dherbey y ed. Gwenwaëlle Aubry (Paris: J. Vrin, 2002), 123.

24 Aristóteles, Política, VII, 1. 


\section{Conclusiones}

La interpretación moderna del pensamiento de Aristóteles sobrestima la importancia del poder político y desconoce la autonomía de la virtud moral. Javier Gomá cita a Hannah Arendt. Ella subestima el valor de la familia y del trabajo frente a la grandeza de la actividad pública. Serían dos esferas completamente separadas. Por un lado, estaría la satisfacción de las tareas domésticas más banales, anónimas y meramente animales, como comer, dormir y procrear, el comercio y la fabricación de instrumentos. Por otro lado, estaría la praxis en la esfera pública con la excelencia heroica, la distinción individual, la libertad, la vida política, la gloria pública, etc. ${ }^{25}$

La modernidad entiende la moral como acciones y no hay espacio para un hombre que busque el bien ético. La razón es instrumental. La filosofía moderna y más la actual cultura tecnócrata entienden la humanidad como el dominio del hombre sobre la naturaleza externa. Sin embargo, la definición de la vida buena no puede hacerse solo a partir de la racionalidad instrumental, sino del interés práctico de las normas morales. Aristóteles considera que se debe definir qué tipo de vida es más deseable. El fin de la sociedad es, por tanto, el bien vivir, y todo está orientado a ese fin. La ciudad es, como decimos, la asociación de familias y aldeas para una vida perfecta y autosuficiente. Y esta es la vida feliz y bella, la vida de amistad.

Efectivamente, Aristóteles entiende la ciudad como el bien superior de las comunidades y comprende a las demás. Afirma que el hombre solo puede realizarse en la polis participando en la política. Esta define toda la vida en la sociedad, pero respeta la autonomía de los agricultores, de los pastores, de los navegantes, de los militares, etc. También respeta la propiedad privada porque lo que es común a muchos obtiene un mínimo de cuidado. Todos se preocupan más de sus cosas propias y menos de lo común. Con mayor razón la política también interviene en la familia, pero para respetarla y apoyarla. Aristóteles critica a Sócrates, que quiere que en la ciudad todo sea unitario (comunismo), ya que por su naturaleza esta implica una cierta pluralidad y al unificarse más y más se destruiría. ${ }^{26}$

25 Javier Gomá, Ejemplaridad pública (Madrid: Santillana Ediciones, 2009), 173-174.

26 Aristóteles, Política, II, 2. 
El ejemplo de las virtudes es la principal fuente de normatividad moral para Aristóteles, pero en nuestra época el encuentro con otra persona no está contemplado como una invitación para aprender los valores. La racionalidad preponderante de la modernidad reemplazó al ejemplo por las leyes abstractas aprobadas en el Congreso nacional. Hoy los ejemplos escasean en la política. Las leyes son conceptos despersonalizados mientras que aquellos tienen el carisma personal. Las leyes coaccionan a los ciudadanos, pero los ejemplos entran en el corazón y lo reforman. ${ }^{27}$

Las personas reciben la educación en las virtudes dentro del ámbito familiar, por los ejemplos de los líderes, por las leyes y por las sanciones de los tribunales. Su vida estará marcada por la virtud cívica y por la virtud ética. La ética recibida en la familia está relacionada con la ciudadanía. La ciudad necesita hombres con capacidad política y con virtud moral.

Aristóteles le da una singular importancia a la familia porque reconoce una cierta autonomía de esta y de la política. Ambas pertenecen a la naturaleza. La familia tiene una serie de características diferentes en relación con otras realidades en la ciudad: el hombre tiende por naturaleza más a vivir en pareja que a ser ciudadano, la relación es de amor familiar y pertenencia no solo por la procreación, sino "por todo lo que implica la vida»; complementándose en las actividades. El amor familiar y la pertenencia constituyen la dignidad; es decir, la educación y la práctica de las virtudes. La educación en familia es mejor que la pública, como señalamos anteriormente.

Aristóteles califica a la familia como una forma particular de amistad -no es solo conveniencia como señalamos antes- y la amistad es el fin de la ciudad. Esta relación de «amor familiar y pertenencia» no existe en otros ambientes en la ciudad. Es una experiencia única de cada familia.

A pesar de que Aristóteles otorgaba a la amistad desinteresada, basada en virtudes, un alta distinción ética, el mundo de las amistades masculinas está recorrido por consideraciones de puro beneficio hasta principios de la Edad Moderna. ${ }^{28}$

27 Javier Gomá, Ejemplaridad pública, 227.

28 Axel Honneth, El Derecho a la libertad, 179. 
Según el mismo autor se ha revivido el pensamiento de Aristóteles según el cual la amistad sin interés es una condición necesaria para una vida individual buena, porque ofrece la oportunidad de obsevar las propias decisiones vitales y revisarlas. En los últimos cincuenta años la familia se ha transformado de una asociación social patriarcal en una relación en la que está intitucionalizada la demanda normativa de brindarse amor unos a otros, solo el afecto mutuo puede constituir una base legítima para el vínculo matrimonial entre el varón y la mujer. ${ }^{29}$

La ciudad y la familia, cada una a su manera, son los fines, pero al mismo tiempo los medios para conseguir el bien que es el fin principal, la vida feliz y bella. Donde hay amistad ya no se necesita la justicia. Axel Honneth considera que la amistad «moderna» supera las fronteras de las clases sociales y las diferencias étnicas. En esta amistad se puede reconocer tal vez el fermento más elemental de toda la eticidad democrática. ${ }^{30}$

Destacados filósofos como John Rawls, Fernando Savater, Luc Ferry, Axel Honneth y otros han mantenido como fundamento el amor familiar. La familia es una amistad particular y la educación en las virtudes es también imprescindible para la política, como afirmaba Aristóteles.

Sin embargo, si se tiene en claro cuánto es lo que depende, en una comunidad democrática, de que sus miembros sean capacitados para un individualismo cooperativo, no se podría poner en duda el significado político-moral de la esfera familiar, puesto que las condiciones psíquicas para casi todas las actitudes que el individuo debe tener, en virtud de sus competencias y sus habilidades individuales para interceder por los asuntos de la comunidad mayor, amén de todos sus vínculos con comunidades particulares, se crean dentro de familias intactas, confiables e igualitarias. ${ }^{29}$

Se puede reconocer en la amistad actual que supera clases sociales y diferencias étnicas, el fermento más elemental de toda la eticidad democrática. ${ }^{30}$

\footnotetext{
$29 \quad$ Ibid., 183 y 221.

$30 \quad$ Ibid., 187.
} 
Los hombres que no aprendieron en la familia a practicar su libertad obedecerán ciegamente en la actualidad a la ideología del gobierno de turno y al poder tecnológico. Martha Nusbaum denuncia la eliminación del arte y de las carreras de humanidades en la educación como una crisis de proporciones gigantescas y de enorme gravedad a nivel mundial. ${ }^{31}$

\section{Bibliografía}

Aristóteles. Ética nicomaquea. Traducido por Patricio de Azcárate. Buenos Aires: Editorial Losada, 2004.

Aristóteles. Ética a Nicómaco. Traducido por Salvador Rus Rufino y Joaquín E. Meabe. Madrid: Editorial Tecnos, 2009.

Aristóteles. Política. Traducido por Carlos García Gual y Aurelio Pérez Jiménez. Madrid: Alianza Editorial, 2018.

Aubry, Gwenwaëlle. «Dunamis et Energeia dans l'Éthique Aristolicienne: l'Éthique du Demonique». En L'excellence de la vie, dirigido por Gilbert Romeyer Dherbey y editado por Gwenwaëlle Aubry, 75-94. Paris: J. Vrin, 2002.

Baricco, Alessandro: The Game. Barcelona: Editorial Anagrama, 2019.

Canto-Sperber, Monique. La morale du monde. Paris: Presse universitaire de France, 2010.

Comte-Sponville, André. Petit traité des grandes vertus. Paris: Presses Universitaires de France, 1995.

Cortina Adela. Ética sin moral. Madrid: Editorial Tecnos, 2008.

Dahrendorf, Ralf. El recomienzo de la historia. Buenos Aires: Katz Editores, 2006.

Donneth, Axel. El derecho de la libertad. Madrid: Katzeditores, 2014.

Ferry, Luc. Familles je vous aime. Paris: XO Éditions, 2007.

Ferry, Luc. La revolution de l'amour. Paris: Editorial Plon, 2010.

Ferry, Luc. De l'Amour. Paris: Odile Jacob, 2012.

Fraile, Guillermo. Historia de la filosofía. Madrid: Biblioteca de Autores Cristianos, 2000.

Gobry, Ivan. La philosophie pratique d'Aristote (Lyon: Presses Universitaires, 1995).

Gomá, Javier. Ejemplaridad pública. Madrid: Santillana Ediciones, 2009.

Gómez, Carlos y Javier Muguerza. La aventura de la moralidad. Madrid: Alianza Editorial, 2007.

Gourinat, Jean Baptiste. «Délibération et choix dans l'éthique aristotélicienne». En L'excellence de la vie, dirigido por Gilbert Romeyer Dherbey y editado por Gwenwaëlle Aubry, 95-124. Paris: J. Vrin, 2002.

Habermas, Jürgen. Ciencia y tecnología. Madrid: Editorial Tecnos, 2013.

Honneth, Axel. El derecho de la libertad. Barcelona: Katz Editores, 2014.

Leuridan Huys, Johan. El sentido de las dimensiones éticas de la vida. Lima: Fondo Editorial de la Universidad de San Martín de Porres, 2019.

31 Martha Nussbaum, Nor for Profit, 2010. 
Murdoch, Iris. On «God» and «Good». London: Chatto \& Windus, 1969.

Nullens, Patrick. Verlangen naar het goede. Zoetermeer: Boekencentrum, 2006.

Nussbaum, Martha. Emociones políticas. Barcelona: Ediciones Paidós, 2014.

Nussbaum, Martha. Crear capacidades. Barcelona: Espasa Libros S. L. U., 2017.

Nussbaum, Martha. Nor for profit. Princeton: Princeton University Press. 2010.

Pieper, Josef. Las virtudes fundamentales. Madrid: Ediciones Rialp, 2007.

Quesada, Fernando. Ética y política. Madrid: Alianza Editorial, 2009.

Romeyer Dherbey, Gilbert, dir. y Gwenwaëlle Aubry, ed. L'excellence de la vie. Paris: J. Vrin, 2002.

Sandel, Michael. Justice. What's the right thing to do? New York: Fara, Strauss, and Giraux, 2010.

Tongeren, Paul van. Een Inleiding in de deugdenethiek. Amsterdam: SUN, 2008.

Vegetti, Mario. «Normal, natural, normatif dans l'Éthique d'Aristote». En L'excellence de la vie, dirigido por Gilbert Romeyer Dherbey y editado por Gwenwaëlle Aubry, 63-74. Paris: J. Vrin, 2002.

Wolton, Dominique. Penser la communication. Paris: Editions Flammarion, 2000. 